\title{
The relation between questions indicating transient ischaemic attack and stroke in 20 years of follow up in men and women in the Renfrew/Paisley Study
}

\author{
C L Hart, D J Hole, G Davey Smith
}

\begin{abstract}
Study objective-Transient ischaemic attack (TIA) is often a precursor to stroke, so identification of people experiencing TIA could assist in stroke prevention by indicating those at high risk of stroke who would benefit most from intervention for other stroke risk factors. The objective of this study was to investigate whether answers to a simple questionnaire for TIA could predict the occurrence of stroke in the following 20 years.

Design-Prospective cohort study, conducted between 1972 and 1976, with 20 years of follow up.

Setting-Renfrew and Paisley, Scotland. Participants-7052 men and 8354 women aged 45-64 years at the time of screening completed a questionnaire and attended a physical examination. The questionnaire asked participants if they had ever, without warning, suddenly lost the power of an arm, suddenly lost the power of a leg, suddenly been unable to speak properly or suddenly lost consciousness. These four questions were taken as indicators of TIA and were related to subsequent stroke mortality or hospital admission.

Main results-For women, each question was significantly related to stroke risk, whereas for men only the question on loss of power of arm was significantly related to stroke risk. Men and women answering two or more questions positively had double the relative rate of stroke compared with men and women answering none of the questions positively, even after adjusting for other risk factors for stroke. Conclusions-A simple questionnaire for TIA could help predict stroke over 20 years of follow up. Targeting men and women who report TIA with early treatment could help to prevent strokes from occurring. (F Epidemiol Community Health 2001;55:653-656)
\end{abstract}

West of Scotland Cancer Surveillance Unit

D J Hole

Department of Social Medicine, University of Bristol, UK

G Davey Smith

Correspondence: Carole Hart

(c.1.hart@udcf.gla.ac.uk)

Accepted for publication 5 April 2001
Tools to determine TIA in population studies could therefore be useful in reducing stroke incidence and mortality through identifying those at high risk of stroke, who have most to gain from interventions for modifiable stroke risk factors. ${ }^{4}$ We have been able to investigate the relation between answers to a questionnaire on TIA in participants of a large cohort study conducted in the 1970s, and subsequent stroke in a long follow up period.

\section{Methods}

The Renfrew/Paisley general population study was carried out between 1972 and 1976 and involved 7052 men and 8354 women aged 45-64 years who were resident in the towns of Renfrew and Paisley in Scotland. A response rate of nearly $80 \%$ was achieved. Full details of the study methodology have been reported previously. ${ }^{56}$ A questionnaire was completed by each participant and was checked when the participant attended a clinic where physical measurements were taken. Participants were asked if they had ever, without warning:

- suddenly lost the power of an arm

- suddenly lost the power of a leg

- suddenly been unable to speak properly

- suddenly lost consciousness.

These four questions were taken to be indicators of a TIA. Men and women who answered yes to a question on previous stroke were excluded from the present analysis, as their stroke may have caused one of more of the TIA symptoms. Participants with missing values for any of the TIA questions were also excluded, leaving 6919 men and 8194 women available for the analysis.

Other questions asked about smoking habit and diabetes. ${ }^{56}$ Cardiovascular symptoms were assessed using the Rose angina questionnaire, with angina defined as definite or possible. ${ }^{8}$ Severe chest pain was defined as ever having a severe pain across the front of the chest lasting half an hour or more. ${ }^{8}$ Social class was defined by the registrar general's classification ${ }^{9}$ based on occupation at time of screening. Participants were asked their regular occupation and if retired, their last full time occupation. Women were given their own occupation, except housewives who were given their husband's or father's occupation. The home address was retrospectively postcoded, enabling deprivation category defined by Carstairs and Morris to be ascertained. ${ }^{10}$ Deprivation category varies from 1 (least deprived) to 7 (most deprived) and is based on four census variables. 
Table 1 Interrelations between answers to TIA questions in 6919 men and 8194 women in the Renfrew/Paisley study

\begin{tabular}{lll}
\hline & \multirow{2}{*}{ Numbers (\%) answering yes } \\
\cline { 2 - 3 } & Men & Women \\
\hline 1 question: & & \\
$\quad$ Have you suddenly lost power of an arm? & $159(2.3)$ & $185(2.3)$ \\
Have you suddenly lost power of a leg? & $159(2.3)$ & $204(2.5)$ \\
Have you suddenly been unable to speak properly? & $103(1.5)$ & $167(2.0)$ \\
Have you suddenly lost consciousness? & $350(5.1)$ & $383(4.7)$ \\
2 questions: & & \\
arm and leg & $54(0.8)$ & $69(0.8)$ \\
arm and speech & $31(0.4)$ & $42(0.5)$ \\
arm and consciousness & $30(0.4)$ & $37(0.5)$ \\
leg and speech & $23(0.3)$ & $45(0.5)$ \\
leg and consciousness & $33(0.5)$ & $48(0.6)$ \\
speech and consciousness & $27(0.4)$ & $39(0.5)$ \\
3 questions: & & \\
arm, leg and speech & $15(0.2)$ & $26(0.3)$ \\
arm, leg and consciousness & $16(0.2)$ & $23(0.3)$ \\
arm, speech and consciounsess & $11(0.2)$ & $15(0.2)$ \\
leg, speech and consciounsess & $8(0.1)$ & $18(0.2)$ \\
All 4 questions: & & \\
arm, leg, speech and consciousness & $7(0.1)$ & $12(0.1)$ \\
\hline
\end{tabular}

Table 2 Age adjusted risk factors by number of TIA questions answered positively

\begin{tabular}{|c|c|c|c|c|}
\hline & \multicolumn{3}{|c|}{ Number of questions answered positively } & \multirow[b]{2}{*}{ Test for trend } \\
\hline & 0 & 1 & 2 or more & \\
\hline \multicolumn{5}{|l|}{ Men } \\
\hline Number & 6303 & 497 & 119 & \\
\hline Mean age ${ }^{\star}$ & 54.1 & 54.6 & 53.7 & $\mathrm{p}=0.31$ \\
\hline Mean SBP & 148.6 & 146.2 & 144.6 & $\mathrm{p}=0.003$ \\
\hline Mean DBP & 86.0 & 85.2 & 85.2 & $\mathrm{p}=0.17$ \\
\hline Mean cholesterol & 5.87 & 5.79 & 5.80 & $\mathrm{p}=0.07$ \\
\hline Mean body mass index & 25.9 & 26.0 & 25.7 & $\mathrm{p}=0.98$ \\
\hline Mean height & 169.7 & 169.0 & 168.5 & $\mathrm{p}=0.004$ \\
\hline Adjusted $\mathrm{FEV}_{1}$ & 89.2 & 85.9 & 81.5 & $\mathrm{p}=0.0001$ \\
\hline$\%$ diabetes & 1.2 & 1.6 & 4.3 & $\mathrm{p}=0.028$ \\
\hline$\%$ pre-existing CHD & 25.3 & 40.8 & 60.7 & $\mathrm{p}=0.0001$ \\
\hline$\%$ current cigarette smokers & 55.9 & 61.5 & 66.0 & $\mathrm{p}=0.001$ \\
\hline$\%$ social class IV and V & 27.6 & 34.5 & 41.8 & $\mathrm{p}=0.0001$ \\
\hline$\%$ deprivation category 6 and 7 & 20.4 & 28.2 & 26.8 & $\mathrm{p}=0.0001$ \\
\hline$\%$ MRC bronchitis & 5.0 & 10.5 & 26.9 & $\mathrm{p}=0.0001$ \\
\hline \multicolumn{5}{|l|}{ Women } \\
\hline Number & 7465 & 577 & 152 & \\
\hline Mean age ${ }^{\star}$ & 54.3 & 54.4 & 54.3 & $\mathrm{p}=0.93$ \\
\hline Mean SBP & 150.2 & 149.3 & 150.1 & $\mathrm{p}=0.51$ \\
\hline Mean DBP & 85.0 & 85.6 & 85.2 & $\mathrm{p}=0.45$ \\
\hline Mean cholesterol & 6.43 & 6.43 & 6.47 & $\mathrm{p}=0.69$ \\
\hline Mean body mass index & 25.7 & 26.3 & 26.3 & $\mathrm{p}=0.002$ \\
\hline Mean height & 157.7 & 157.4 & 156.6 & $\mathrm{p}=0.013$ \\
\hline Adjusted $\mathrm{FEV}_{1}$ & 93.2 & 89.2 & 83.1 & $\mathrm{p}=0.0001$ \\
\hline$\%$ diabetes & 1.1 & 1.6 & 1.9 & $\mathrm{p}=0.16$ \\
\hline$\%$ pre-existing CHD & 23.3 & 44.9 & 62.1 & $\mathrm{p}=0.0001$ \\
\hline$\%$ current cigarette smokers & 45.9 & 53.1 & 55.7 & $\mathrm{p}=0.0002$ \\
\hline$\%$ social class IV and V & 38.1 & 43.4 & 40.8 & $\mathrm{p}=0.030$ \\
\hline$\%$ deprivation category 6 and 7 & 22.4 & 24.8 & 29.6 & $\mathrm{p}=0.015$ \\
\hline$\%$ MRC bronchitis & 3.4 & 9.0 & 19.4 & $\mathrm{p}=0.0001$ \\
\hline
\end{tabular}

${ }^{\star}$ Not age adjusted.

At the screening examination, blood pressure was recorded as the mean of two measurements taken in the seated position. ${ }^{5}$ A non-fasting blood sample was taken for the measurement of plasma cholesterol. ${ }^{5}$ Measurements of height and weight were made, enabling body mass index in $\mathrm{kg} / \mathrm{m}^{2}$ to be calculated.

The forced expiratory volume in one second $\left(\mathrm{FEV}_{1}\right)$ was measured at the screening examination using a vitalograph spirometer. The $\mathrm{FEV}_{1}$ score was calculated by obtaining the expected $\mathrm{FEV}_{1}$ from a linear regression equation of age and height for men and women separately, derived from a healthy subset of the population. ${ }^{6}$ Adjusted $\mathrm{FEV}_{1}$ was defined as actual $\mathrm{FEV}_{1}$ as a percentage of expected $\mathrm{FEV}_{1}$.

A six lead electrocardiogram was coded according to the Minnesota system. ${ }^{11}$ Ischaemia on ECG was defined as codes 1.1-1.3, 4.1-4.4,
KEY POINTS

- Transient ischaemic attack (TIA) often precedes a stroke.

- Responses to four questions indicating previous TIA were related to stroke over 20 years of follow up.

- Men and women answering two or more questions positively had double the risk of stroke.

- Targeting men and women who report TIA with early treatment could aid stroke prevention.

5.1-5.3 or 7.1. Pre-existing coronary heart disease (CHD) was defined as having any of angina, ECG ischaemia or severe chest pain.

Study participants were flagged at the National Health Service Central Register in Edinburgh. Dates and cause of death occurring in the United Kingdom were provided, with stroke defined as ICD9 codes 430-438. Additionally, a computerised linkage with acute hospital discharges in Scotland provided records of all diagnoses of stroke between 1972 and $1995^{12}$ that entailed an inpatient stay in Scotland. There was no information available on hospital admissions for stroke in the rest of the United Kingdom or on non-fatal stokes that occurred without a hospital admission. Stroke was defined as either having a hospital admission with a main diagnosis of stroke or dying of stroke in the 20 year follow up period.

Age adjusted means for continuous variables were calculated using PROC GLM of the SAS system. Categorical variables were age standardised by the direct method, using the study populations as the standard. Cox's models ${ }^{13}$ were used to calculate proportional hazards regression coefficients by answers to the TIA questions. Adjustments were made for other variables by including them in the models. Survival time was taken from date of screening until either date of hospital admission for stroke, or date of death from stroke if no hospital admission for stroke were found. Analyses were performed separately for men and women.

\section{Results}

Small proportions answered "yes" to each TIA question, with the highest number of positive responses being given to the question on lost consciousness (table 1). Very few answered "yes" to all four questions. There was no significant difference between men and women in the answers to the questions on loss of power of arm, leg or loss of consciousness (age adjusted odds ratios 0.99 (95\% confidence intervals $0.80,1.22), 1.09(0.88,1.34)$ and $0.92(0.79,1.06)$ respectively). However, women were significantly more likely than men to report suddenly being unable to speak properly (odds ratio $1.38(1.08,1.77)$ ).

Men and women who answered "yes" to individual TIA questions were, in general, less healthy than those answering "no", for example having poorer lung function and being more 
Table 3 Relative rates of stroke in 20 years by TIA questions, estimated by Cox proportional hazards models

\begin{tabular}{|c|c|c|c|c|}
\hline & \multicolumn{2}{|l|}{ Men } & \multicolumn{2}{|c|}{ Women } \\
\hline & \multicolumn{2}{|c|}{ Suddenly lost the power of an arm } & No & Yes \\
\hline \multirow{2}{*}{$\begin{array}{l}\text { Strokes } \\
\text { Relative rate adjusted for: }\end{array}$} & 560 & 23 & 641 & 26 \\
\hline & & & & \\
\hline \multirow{4}{*}{$\begin{array}{l}\text { Age } \\
\text { All risk factors }\end{array}$} & 1 & $2.12(1.39,3.21)$ & 1 & $2.14(1.44,3.16)$ \\
\hline & 1 & $1.74(1.14,2.66)$ & 1 & $1.67(1.12,2.50)$ \\
\hline & \multicolumn{4}{|c|}{ Suddenly lost the power of a leg } \\
\hline & No & Yes & No & Yes \\
\hline Strokes & 568 & 15 & 640 & 27 \\
\hline \multicolumn{5}{|l|}{ Relative rate adjusted for: } \\
\hline Age & 1 & $1.30(0.78,2.17)$ & 1 & $2.01(1.37,2.96)$ \\
\hline \multirow[t]{3}{*}{ All risk factors* } & & $1.09(0.65,1.82)$ & 1 & $1.80(1.22,2.66)$ \\
\hline & \multicolumn{4}{|c|}{ Suddenly been unable to speak properly } \\
\hline & No & Yes & No & Yes \\
\hline Strokes & 572 & 11 & 648 & 19 \\
\hline \multicolumn{5}{|l|}{ Relative rate adjusted for: } \\
\hline Age & 1 & $1.56(0.86,2.83)$ & 1 & $1.64(1.04,2.60)$ \\
\hline \multirow[t]{3}{*}{ All risk factors* } & 1 & $1.36(0.74,2.49)$ & 1 & $1.40(0.88,2.22)$ \\
\hline & \multicolumn{4}{|c|}{ Suddenly lost consciousness } \\
\hline & No & Yes & No & Yes \\
\hline Strokes & 548 & 35 & 620 & 47 \\
\hline \multicolumn{5}{|l|}{ Relative rate adjusted for: } \\
\hline Age & 1 & $1.15(0.82,1.62)$ & 1 & $1.55(1.15,2.09)$ \\
\hline \multirow[t]{3}{*}{ All risk factors* } & & $1.11(0.78,1.56)$ & 1 & $1.42(1.05,1.91)$ \\
\hline & \multicolumn{4}{|c|}{ Answered yes to any of the four questions } \\
\hline & No & Yes & No & Yes \\
\hline Number & 6303 & 616 & 7465 & 729 \\
\hline Strokes & 522 & 61 & 586 & 81 \\
\hline \multicolumn{5}{|l|}{ Relative rate adjusted for: } \\
\hline Age & 1 & $1.25(0.96,1.63)$ & 1 & $1.54(1.22,1.94)$ \\
\hline All risk factors* & 1 & $1.15(0.88,1.50)$ & 1 & $1.34(1.05,1.69)$ \\
\hline
\end{tabular}

*Adjusted for age, smoking, systolic blood pressure, diastolic blood pressure, diabetes, pre-existing $\mathrm{CHD}$, adjusted $\mathrm{FEV}_{1}, \mathrm{MRC}$ bronchitis, social class and deprivation category.

Table 4 Relative rates of stroke in 20 years by number of TIA questions answered positively, estimated by Cox proportional hazards models

\begin{tabular}{|c|c|c|c|}
\hline & \multicolumn{3}{|c|}{ Number of questions answered positively } \\
\hline & 0 & 1 & 2 or more \\
\hline \multicolumn{4}{|l|}{ Men } \\
\hline Number & 6303 & 497 & 119 \\
\hline Strokes & 522 & 43 & 18 \\
\hline \multicolumn{4}{|c|}{ Relative rate adjusted for: } \\
\hline Age & 1 & $1.06(0.77,1.44)$ & $2.26(1.41,3.62)$ \\
\hline All risk factors $\star$ & 1 & $0.99(0.72,1.35)$ & $1.95(1.20,3.16)$ \\
\hline \multicolumn{4}{|l|}{ Women } \\
\hline Number & 7465 & 577 & 152 \\
\hline Strokes & 586 & 57 & 24 \\
\hline \multicolumn{4}{|c|}{ Relative rate adjusted for: } \\
\hline Age & 1 & $1.33(1.02,1.75)$ & $2.43(1.62,3.66)$ \\
\hline All risk factors $\star$ & 1 & $1.15(0.87,1.51)$ & $2.21(1.46,3.36)$ \\
\hline
\end{tabular}

^Adjusted for age, smoking, systolic blood pressure, diastolic blood pressure, diabetes, pre-existing $\mathrm{CHD}$, adjusted $\mathrm{FEV}_{1}, \mathrm{MRC}$ bronchitis, social class and deprivation category.

likely to have bronchitis (table available from authors).

There were significant trends with number of questions answered positively for men and women for height and adjusted $\mathrm{FEV}_{1}$ (inversely) and for pre-existing CHD, smoking, poor social class, deprivation category and bronchitis (positively) (table 2). For men only there were significant inverse trends for systolic blood pressure and significant positive trends for diabetes. For women only there was a significant positive trend for body mass index.

Altogether 583 men and 667 women had a hospital admission for stroke or died of stroke in the 20 year follow up period. The age adjusted 20 year stroke rate was 64.8 per 10000 person years for men and 52.0 per
10000 person years for women. Men and women who reported loss of power of an arm were more than twice as likely to have a stroke than men and women who answered "no" (table 3). Adjusting for risk factors attenuated the relative rates, but they were still raised and statistically significant. There were significantly higher relative rates of stroke for women, but not men, who reported loss of power of a leg, speech, loss of consciousness, or gave a positive answer to any of the TIA questions. There were no significant interactions for sex with each individual question. Adjusting for age and answers to the other three TIA questions produced significant relative rates for the question on loss of power of arm for men and women, and significant relative rates for the question on loss of consciousness for women only. When the follow up period was divided into four five year periods, strokes were more likely to occur in the later periods (the distribution of strokes in the four periods was $10 \%, 19 \%, 29 \%$ and $41 \%$ ). However, men and women who answered any of the four TIA questions positively were more likely to have a stroke in the first five years of follow up than men and women not answering positively to any of the questions. The percentages for the five year periods were $21 \%, 15 \%, 30 \%$ and $34 \%$ for those answering positively and $9 \%$, $20 \%, 29 \%$ and $42 \%$ for those not answering positively.

Men and women answering two or more questions positively had double the relative rate of stroke compared with men and women answering none of the questions positively (table 4). Adjustment for risk factors attenuated the relative rates, although they remained significant at conventional levels. Women who answered one question positively also had a significantly higher relative rate of stroke, which was nonsignificant after adjustment for risk factors. Further analysis of specific pairs of questions compared with negative answers to all questions showed all pairs to have significantly higher age adjusted relative rates for women, and all pairs containing loss of consciousness to have significant relative rates for men.

\section{Discussion}

We have shown a relation between answers to TIA questions and subsequent stroke risk. The strongest and most consistent of the questions for both men and women seemed to be the one relating to the loss of power in an arm. The other three questions did not predict stroke in men, although they did for women. Comparison of participants answering "yes" to any of the four questions with participants answering "no" to all four questions also produced different results for men and women, with significant results seen only for women. It is not clear whether women answered the questions in a different way from men, or whether women with TIA symptoms have a greater risk of stroke than men with TIA symptoms. It is possible that for men a sudden loss of power in a leg is more likely to indicate nerve entrapment than cerebral ischaemia, given that men have a 
higher risk than women of such back problems. ${ }^{14}$ Analysis of specific pairs of questions highlighted the importance to stroke risk of loss of consciousness together with another positive answer. This could reflect loss of consciousness on its own being related to other factors (for example postural hypotension), but in combination with other symptoms it being a good indicator of experience of a TIA.

Other TIA questionnaires in use at the time of the study used different questions: the Copenhagen city heart study asked five questions (blurring or loss of vision, double vision, limb paresis, speech disturbance and dysequilibrium). ${ }^{2}$ The Joint Committee for Stroke suggested a very detailed questionnaire, asking about frequency and length of attacks for five domains (numbness or tingling, paralysis, vision, speech and dizziness) ${ }^{1}$ and a similar questionnaire was used in a large survey of elderly persons. ${ }^{15}$ In the 1980 s, the Tromsø study used three questions (paralysis, speech, vision) ${ }^{16}$ and the ARIC study asked about loss of vision, double vision, speech dysfunction, weakness or paralysis, numbness or tingling, and dizziness. ${ }^{17}$ Other studies then investigated participants answering the TIA questions positively more completely, by further questioning and physical examination, ${ }^{21618}$ to find out if the symptoms were attributable to a TIA or to other causes (for example, ophthalmological problems, dizziness on standing up, migraine, nerve entrapment). In the current study, there was no further follow up of this type. Therefore participants classified as having TIA from our questionnaire are likely to include false positives. Screening questionnaires should ideally contain queries to eliminate nonspecific questions. ${ }^{15}$

There have been few studies with long term follow up and they typically contained small numbers. Other studies in the literature generally had higher risks of stroke than the current study found. In Evans County, 28 of 2455 participants had TIA and two of these had a stroke after three to five years. ${ }^{18}$ In the Tromsø study, all 26 TIA cases remained stroke free in 55 months. ${ }^{16}$ In the Oxfordshire Community Stroke project, there was a 13 -fold excess risk of stroke in the first year among 184 TIA cases and a sevenfold risk in seven years of follow up. ${ }^{19} \mathrm{~A}$ case-control study of TIA cases found a 4.5-fold adjusted hazard ratio for fatal or nonfatal stroke. ${ }^{20}$ A TIA aspirin trial reported 230 strokes in 2435 people with recent TIA in four years follow up. ${ }^{21}$

There are several limitations of our study. The TIA questionnaire was non-standard and the risk factors were based on one baseline survey. It is possible that the symptoms reported were attributable to other diseases and not TIA. However, more strokes occurred in the first five years of follow up in participants who answered any of the questions positively than participants not answering any of the questions positively. TIA diagnosis from questionnaire is different from TIA detected in the clinical setting, the second being likely to be more serious. Some participants in this study may have sought medical treatment, although we cannot tell. However, these simple questions identified people with more than double the risk of stroke, which compares favourably to the analogous use of the Rose angina questionnaire as a predictor of coronary heart disease mortality. ${ }^{8}$ The TIA questions could be used as quick and simple indicators of those at high risk of stroke, who have most to gain from interventions for modifiable cardiovascular disease risk factors. ${ }^{4}$

To conclude, we have demonstrated that a simple questionnaire for TIA can predict stroke in 20 years of follow up. Use of such a questionnaire to detect those at risk could help prevent strokes by targeting early preventative treatment.

Pauline MacKinnon is responsible for updating mortality in the Renfrew/Paisley cohort.

Funding: funding was provided by Chest, Heart and Stroke Scotland, and the Stroke Association.

Conflicts of interest: none.

1 Heyman A, Leviton A, Millikan CH, et al. Transient focal cerebral ischemia: epidemiological and clinical aspects. Cerebral ischemia: ep

2 Boysen G, Jensen G, Schnohr P. Frequency of focal cerebral transient ischemic attacks during a 12 month period. Stroke 1979;10:533-4.

3 Ebrahim S, Harwood R. Stroke. Epidemiology, evidence, and clinical practice. Oxford: Oxford University Press, 1999.

4 Davey Smith G, Egger M. Who benefits from medical interventions? $B M \mathcal{F}$ 1994;308:72-4.

5 Hawthorne VM, Watt GCM, Hart CL, et al. Cardiorespiratory disease in men and women in urban Scotland: baseline characteristics of the Renfrew/Paisley (Midspan) Study population. Scott Med F 1995;40:102-7.

6 Hole DJ, Watt GCM, Davey Smith G, et al. Impaired lung function and mortality risk in men and women: Findings from the Renfrew and Paisley prospective population study. BMF 1996;313:711-16.

7 Rose GA. The diagnosis of ischaemic heart pain and intermittent claudication in field surveys. Bull World Health Organ 1962;27:645-58.

8 Hart CL, Watt GCM, Davey Smith G, et al. Pre-existing schaemic heart disease and ischaemic heart disease mortality in women compared with men. Int $\mathcal{F}$ Epidemiol 1997;26:508-15.

9 General Register Office. Classification of occupations 1966. London: HMSO, 1966.

10 Carstairs V, Morris R. Deprivation and health in Scotland. Aberdeen: Aberdeen University Press, 1991

11 Prineas RJ, Crow RS, Blackburn H. The Minnesota code manual of electrocardiographic findings: standards and procedures for measurement and classification. Boston, MA: John Wright, 1982

12 Hanlon P, Walsh D, Whyte B, et al. Hospital use by an ageing cohort: an investigation into the association between biological, behavioural and social risk markers and subsequent hospital utilization. $\mathcal{f}$ Public Health Med 1998;20:467-76.

13 Cox DR. Regression models and life tables. Fournal of the Royal Statistical Society (B) 1972;34:187-220.

14 Heliovaara M, Impivaara O, Sievers K, et al. Lumbar disc syndrome in Finland. $\mathcal{F}$ Epidemiol Community Health 1987; 41:251-8.

15 Wilkinson WE, Heyman A, Burch JG, et al. Use of a self-administered questionnaire for detection of transient cerebral ischemic attacks: 1 . Survey of elderly persons living in retirement facilities. Ann Neurol 1979;6:40-6.

16 Johnson SE, Skre H. Transient cerebral ischemic attacks in the young and middle aged. A population study. Stroke 1986;17:662-6.

17 Chambless LE, Shahar E, Sharrett AR, et al. Association of transient ischemic attack/stroke symptoms assessed by standardized questionnaire and algorithm with cerebrovascular risk factors and carotid artery wall thickness: The ARIC study, 1987-1989. Am f Epidemiol 1996;144:85766.

18 Karp HR, Heyman A, Heyden S, et al. Transient cerebral ischemia. Prevalence and prognosis in a biracial rural comischemia. Prevalence and prognosity.

19 Dennis M, Bamford J, Sandercock P, et al. Prognosis of transient ischemic attacks in the Oxfordshire Community transient ischemic attacks in the Oxford
Stroke Project. Stroke 1990;21:848-53.

20 Howard G, Evans GW, Crouse III JR, et al. A prospective reevaluation of transient ischemic attacks as a risk factor for death and fatal or nonfatal cardiovascular events. Stroke 1994;25:342-5.

21 Rodgers A, MacMahon S, Gamble G, et al. Blood pressure and risk of stroke in patients with cerebrovascular disease. $B M \mathcal{F}$ 1996;313:147. 